\title{
Influence of Early Oven Curing on the Alkali Activated Binders with Reactive Magnesia Replacement
}

\section{Shaoqin Ruan, Gediminas Kastiukas, Shuang Liang, and Xiangming Zhou}

Department of Civil and Environmental Engineering, Brunel University London, Kingston Ln, London, Uxbridge UB8 3PH, United Kingdom

\section{Abstract}

Magnesia is widely used an expansive agent in construction materials due to its delayed hydration, which will compensate for the thermal shrinkage. This study investigates the influence of magnesia and early oven curing on the mechanical performance and microstructures of alkali-activated natural clay samples under different curing regimes after 28 days. Microstructural analysis and $\mathrm{pH}$ measurements were conducted to assess the strength of the samples. Results indicate that the strength was greatly improved (in comparison with the control samples) by the incorporation of magnesia due to the

Corresponding Author: Xiangming Zhou xiangming.zhou@brunel.ac.uk

Received: 20 March 2020

Accepted: 30 April 2020

Published: 13 April 2020

Publishing services provided by Knowledge E

(c) Shaoqin Ruan et al. This article is distributed under the terms of the Creative Commons Attribution License, which permits unrestricted use and redistribution provided that the original author and source are credited.

Selection and Peer-review under the responsibility of the RICON19 - REMINE International Conference Conference Committee. formation of nesquehonite. Meanwhile, oven curing is an effective method in the fast strength development in alkali-activated natural clay. The results also demonstrated the possibility of $\mathrm{CO}_{2}$ curing in the strength development of the magnesia-modified alkali-activated natural clay.

Keywords: magnesia, natural clay, oven curing, compressive strength, microstructure

\section{Introduction}

Clay or calcined clay are often identified as alternatives to Portland cement (PC) to form blended binders [1], and the blended binders incorporating PC and (calcined) clay presented excellent mechanical performance due to the pozzolanic effect of the precursor [2]. The performance of alkali-activated (calcined) clay samples have been widely investigated, which are free of PC, due to their low cost and environmental burdens associated with their preparation [3], and the strength of samples was greatly improved due to the formation of some hydration products such as calcium (aluminium) silicate hydrates (C-(A)-S-H) under a high pH environment [3].

Some studies also indicated that using quicklime or magnesia to stabilize the GGBSclay binders and reported that the strength of the binders was greatly improved compared with the control clay binders [4], as well as the durability of samples under water [3] since alkali-activated natural clay showed a relatively weak water resistance. 
In terms of the treatment of alkali-activated binders or geopolymer, the oven curing has been utilized since it promoted the hydration degree of precursors, leading to a higher amount of hydration products and improved mechanical performance [22].

Therefore, this study tried to combine the oven curing and reactive magnesia replacement when preparing the alkali-activated natural clay to further improve the hydration degree of binders as well as the mechanical performance, and the microstructural analysis was also employed to explain the results.

\section{Materials, Binder Preparation and Methods}

\subsection{Materials and binder preparation}

The natural clay used in this study is a type of waste, received from Green INSTRUCT partner in Poland. The sodium carbonate $\left(\mathrm{Na}_{2} \mathrm{CO}_{3}\right)$ was used to provide a high $\mathrm{pH}$ environment, purchased from Sigma-Aldrich, United Kingdom. The reactive magnesia (Magnesia GmBH, Germany) was used as replacement of natural clay. After the mixing of paste, they were poured into $50 * 50 * 50 \mathrm{~mm}$ cubes, and two curing conditions were utilized: (1) Normal curing (i.e. room temperature) up to 28 days; (2) Mixed curing: oven curing (i.e. $80^{\circ} \mathrm{C}$ ) for three days plus normal curing until 28 days. The mix formulation can be found in Table 1.

TABLE 1: Mix formulation in this study

\begin{tabular}{|c|c|c|c|c|c|}
\hline Group & $\begin{array}{c}\text { Calcined } \\
\text { clay }\end{array}$ & $\mathrm{Na}_{2} \mathrm{CO}_{3}$ & Magnesia & $\begin{array}{l}\text { w/b } \\
\text { ratio }\end{array}$ & $\begin{array}{l}\text { Curing } \\
\text { regimes }\end{array}$ \\
\hline M20-NC & $80 \%$ & & $20 \%$ & 0.41 & $\begin{array}{c}\text { Normal } \\
\text { curing }\end{array}$ \\
\hline C-OC & $100 \%$ & $10 \%$ & 0 & 0.34 & $\begin{array}{l}\text { Mixed } \\
\text { curing: } \\
\text { (oven }\end{array}$ \\
\hline M20-OC & $80 \%$ & & $20 \%$ & 0.41 & $\begin{array}{l}\text { and } \\
\text { normal } \\
\text { curing) }\end{array}$ \\
\hline
\end{tabular}

\subsection{Methodology}

The compressive strength was tested after 28 days in triplicates in line with the standard ASTM C109/C109M-13 with the use of 50-kN Instron 5960 universal testing machine 
under a loading rate of $12.7 \mathrm{~mm} / \mathrm{min}$. Then the residuals were ground to powders and the $\mathrm{pH}$ values were measured with the use of calibrated Mettler Toledo $\mathrm{pH}$ meter according to ASTM C25. Prior to each measurement, five grams of fines powders were intermixed with 100 grams of distilled water and they were mixed for five minutes. In terms of the microstructural analysis, scanning electron microscope (SEM) was also used via a Zeiss Supra 35VP to explain the strength results.

\section{Results and Discussion}

\subsection{Results}

\subsubsection{Mechanical performance}

The compressive strength values of selected samples are shown in Figure 1. As can be seen from the figure, the use of magnesia in samples greatly improved the mechanical performance under normal curing compared with the control group under mixed curing (early-age oven curing+normal curing), which is related with the low $\mathrm{pH}$ values provided by the sole use of $\mathrm{Na}_{2} \mathrm{CO}_{3}$, and meanwhile, in addition to the $\mathrm{pH}$ increment, the incorporation of magnesia also led to the formation of new hydration phases, contributing the strength development of samples, which will be elaborated in Section 3.1.2.

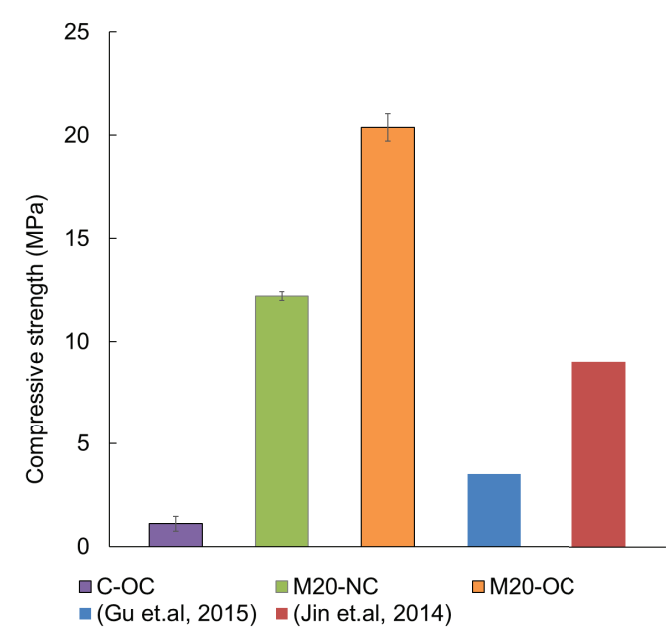

Figure 1: A comparison between the compressive strength of selected samples and values from literatures $[3,5]$ after 28 days of curing

When comparing the influence of different curing regimes on the mechanical performance of magnesia-based binders, the involvement of oven curing led to $66.7 \%$ increase of strength compared with binders subjected to normal curing, which is related with the acceleration of the hydration process of binders under high temperature curing. 
Meanwhile, when comparing the strength reported by literatures $[3,5]$, the strength values of clay samples investigated in this study are much higher, which could be related with different formation of hydration phases, shown in Section 3.1.2.

\subsection{2. $\mathrm{pH}$ values}

The $\mathrm{pH}$ values of selected samples are presented in Figure 2. The figure clearly indicated that the incorporation of magnesia in alkali-activated natural clay samples led to an increase of $\mathrm{pH}$ values, accounting for the activation efficiency of the natural clay with magnesia replacement irrespective of curing regime. Meanwhile, it is to be noted that mixed curing caused lower $\mathrm{pH}$ values of samples compared with normal curing, which could be related with the formation of a higher amount of hydration phases due to the accelerated hydration kinetics, and a larger amount of hydration products formed would undoubtedly combine or absorb a higher content of $\mathrm{OH}^{-}$in pore solution, which led to lower $\mathrm{pH}$ values of samples under mixed curing.

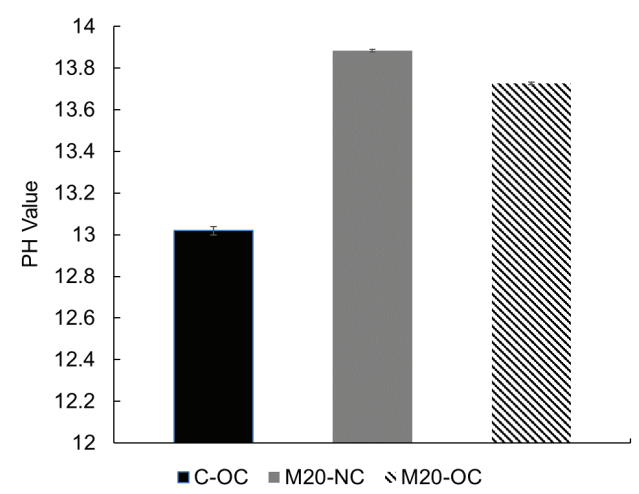

Figure 2: $\mathrm{pH}$ values of selected samples after 28 days of curing

\subsubsection{Microstructures}

Fig. 3 shows SEM image of M20-OC after 28 days of mixed curing. The extensive presence of crystals can be referred to the formation of nesquehonite [6], which may greatly contribute to the strength development compared with $\mathrm{C}-(\mathrm{A})-\mathrm{S}-\mathrm{H}$ (it was widely reported by other studies $[3,5])$, and the chemical reaction of nesquehonite formation is shown in Equation (1).

$$
\mathrm{Mg}^{2+}+\mathrm{CO}_{3}{ }^{2-}+3 \mathrm{H}_{2} \mathrm{O} \rightarrow \mathrm{MgCO}_{3} \cdot 3 \mathrm{H}_{2} \mathrm{O}
$$

The interlocking effects of these fibrous crystals greatly contributed to the strength development of samples, and due to the 3D nature of these crystals, the nesquehonite 


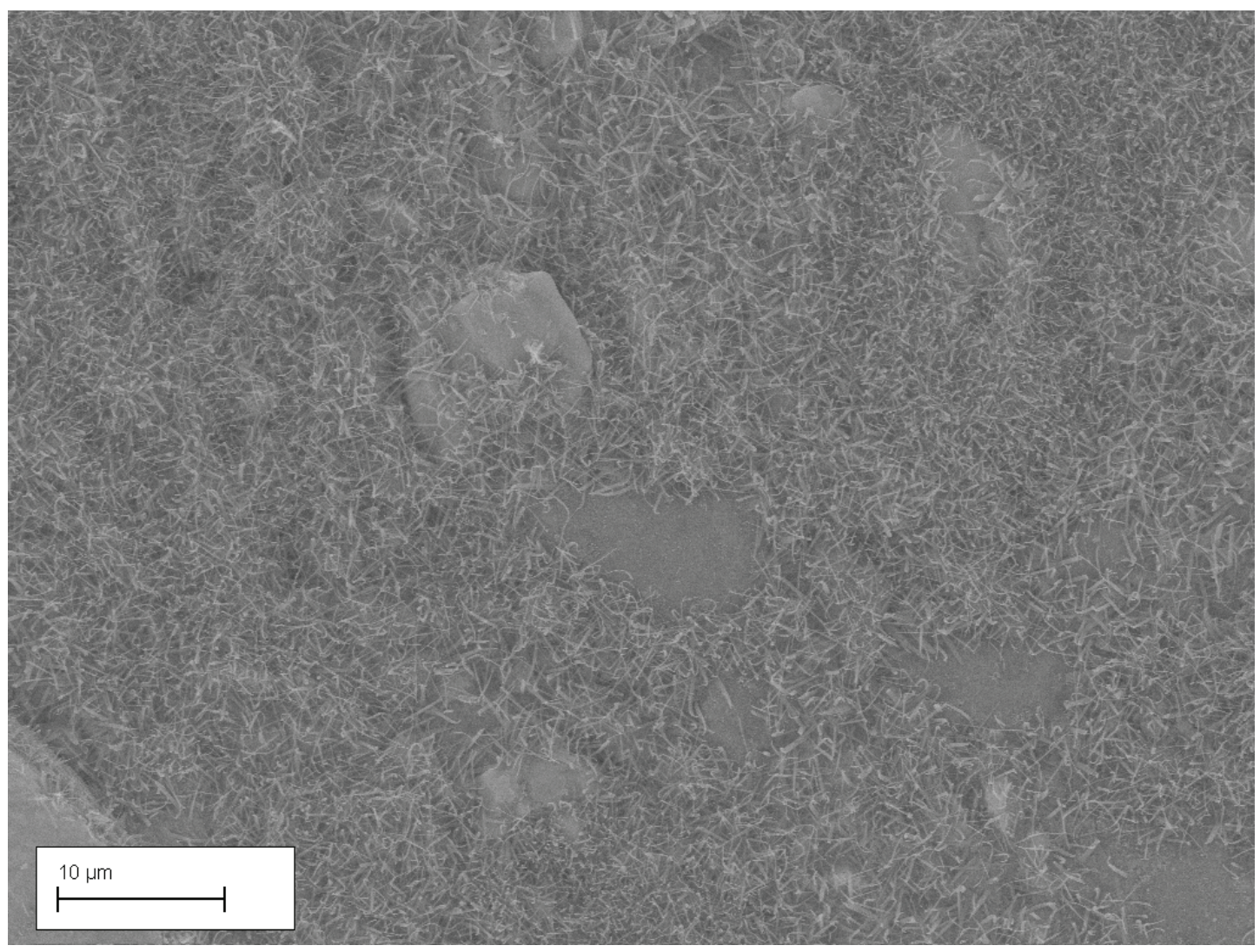

Figure 3: Microstructure of M20-OC

is more useful in terms of the further improvement of compressive strength compared with $\mathrm{C}-(\mathrm{A})-\mathrm{S}-\mathrm{H}$.

\subsection{Discussion}

\subsubsection{Expansion of magnesia}

The early-age oven curing may have two-fold influences on the strength development of alkali-activated samples: (1) it may accelerate the hydration kinetics and improve the mechanical performance of binder; $(2)$ it is reported that alkali activated binders may experience shrinkage or micro-cracking [7], and higher temperature curing may further accelerate this process and lead to inferior mechanical performance, however, the shrinkage or micro-cracking of magnesia-based group can be alleviated or avoided by the use of magnesia, which presents a delayed volume expansion of $118 \%$ when $\mathrm{MgO}$ is converted into $\mathrm{Mg}(\mathrm{OH})_{2}$, and Figure 4 displays the models [8] that were used to explain the expansion of magnesia with different reactivity. 


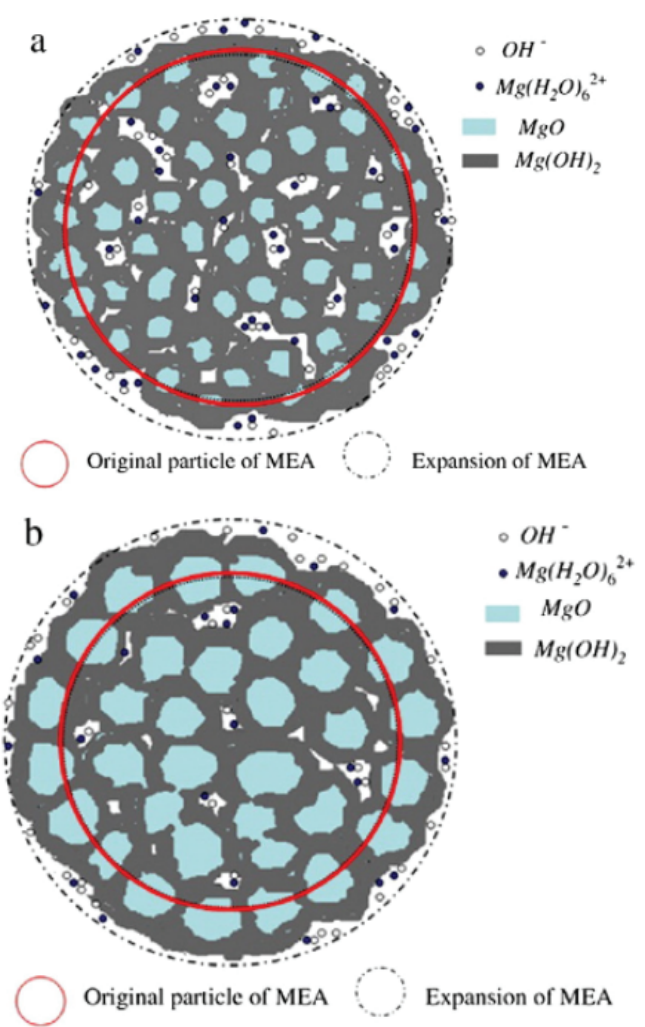

Figure 4: Models [8] used to explain the expansion of magnesia (a) with high reactivity and (b) with low reactivity

In view of this, early-age oven curing is identified as a useful technique to facilitate the strength development of magnesia-based samples without severe shrinkage or micro-cracking.

\subsubsection{Potential use of $\mathrm{CO}_{2}$ curing in alkali-activated natural clay binder}

Early-age oven curing may accelerate the strength development of alkali-activated natural clay binder with reactive magnesia replacement, however, this process is still energy-intensive. Therefore, other techniques such as accelerated $\mathrm{CO}_{2}$ curing may be used to facilitate the strength development. It is reported that the carbonation of reactive magnesia would lead to a great strength improvement $[6,9,10]$, which is related with the formation of a series of hydrated magnesium carbonates, meanwhile, the porosity of samples was greatly reduced and the microstructures of the samples became more compacted compared with that of un-carbonated samples. 


\section{Conclusions}

In addition to provide a more alkaline environment, the use of magnesia also provided additional $\mathrm{Mg}^{2+}$ to form nesquehonite, which contributed to the strength development of alkali-activated natural clay binders greatly due to the interlocking effect and 3D nature compared with C-(A)-S-H. Meanwhile, the delayed hydration process of magnesia may reduce the shrinkage and the occurrence of micro-cracking. Further, in the future, to reduce the energy consumption, accelerated $\mathrm{CO}_{2}$ curing may be a more eco-friendly technique to stabilize the natural clay samples.

\section{Funding}

Finance support from the European Commission Horizon 2020 Research and Innovation Programme through the grant 723825 (i.e. the Green INSTRUCT project) is greatly acknowledged.

\section{Acknowledgements}

The authors wants to express thanks to the help provided by ETC in Brunel University London.

\section{References}

[1] Kani, E.N., Allahverdi, A. and Provis, J.L. (2017). Calorimetric study of geopolymer binders based on natural pozzolan. Journal of Thermal Analysis and Calorimetry, vol. 127, pp. 2181-2190.

[2] Singh, M. and Garg, M. (2006). Reactive pozzolana from Indian clays-their use in cement mortars. Cement and Concrete Research, vol. 36, pp. 1903-1907.

[3] Gu, K., et al. (2015). Incorporation of reactive magnesia and quicklime in sustainable binders for soil stabilisation. Engineering Geology, vol. 195, pp. 53-62.

[4] Yi, Y., et al. (2016). Magnesia reactivity on activating efficacy for ground granulated blast furnace slag for soft clay stabilisation. Applied Clay Science, vol. 126, pp. 57-62.

[5] Jin, F. and Al-Tabbaa, A. (2014). Strength and hydration products of reactive MgOsilica pastes. Cement and Concrete Composites, vol. 52, pp. 27-33.

[6] Ruan, S. and Unluer, C. (2007). Influence of mix design on the carbonation, mechanical properties and microstructure of reactive $\mathrm{MgO}$ cement-based concrete. 
Cement and Concrete Composites, vol. 80, pp. 104-114.

[7] Neto, A.A.M., Cincotto, M.A., and Repette, W. (2008). Drying and autogenous shrinkage of pastes and mortars with activated slag cement. Cement and Concrete Research, vol. 38, pp. 565-574.

[8] Mo, L., Deng, M. and Tang, M. (2010). Effects of calcination condition on expansion property of MgO-type expansive agent used in cement-based materials. Cement and Concrete Research, vol. 40, pp. 437-446.

[9] Ruan, S. and Unluer, C. (2017). Effect of air entrainment on the performance of reactive $\mathrm{MgO}$ and PC mixes. Construction and Building Materials, vol.142, pp. 221-232.

[10] Ruan, S., et al. (2017). Performance and microstructure of calcined dolomite and reactive magnesia-based concrete samples. Journal of Materials in Civil Engineering, vol. 29, p. 04017236. 